\title{
The Detection of the Deffect of Short Circuit in a Permanent Magnets Synchronous Machine by The Power spectral Density
}

\author{
A.Ourici
}

\begin{abstract}
The work suggested in this article consists of the detection of a three-phase short circuit

in a synchronous permanent magnets machine supplied with a three levels inverter of voltage PWM, by the means of the spectral analysis of the stator currents.

The practice showed that at the time of a short circuit it is primarily the stator resistance which considerably will increase. For that we establish the model of the operational engine first of all. Then we will give the model of the engine weakening and will treat the results of simulation for finally comparing the spectra of harmonics of the currents of the two models.

The early knowledge of such a defect starting from a simple spectrogram makes it possible to avoid the total dysfunction of the machine
\end{abstract}

Keywords - Inverter of voltage PWM on three levels, synchronous machine with permanent magnets, defect of short circuit, spectra analyzes, power spectral density, torque and stator current oscillations.

\section{INTRODUCTION}

The technological developments allowed the electric machines, in particular synchronous one, to find the flexibility of control and the dynamic performances naturally obtained with the machine with continuous current

[ Boucherit 95], [ Bose 86 ] in addition with the development of new material, like the permanent magnets containing rare earth, these synchronous machines present many advantages compared to the other machines, a weak inertia and a raised mass couple, unfortunately, these machines as all the others are prone to considerable malfunctions in particular the short-circuits.

The defects which appear in the electric machines have varied causes :

they can be due to the ageing of the components of the engine or to the conditions of use or quite simply to a manufacturing defect of which the effect would be unperceivable at the time of the startup. In order to avoid spurious shutdowns, and with the development of sensors of monitoring and detection of breakdown, it is possible to diagnose various types of defects and to cure it.

The purpose of our paper is the detection of a three-phase

Department of Electrical engineering - Faculty of Science of the engineer University Badji Mokhtar-Annaba, BP 12 Annaba -Algeria

(amel.ourici @hotmail.com). short circuit in a synchronous permanent magnets machine supplied with a three levels inverter of voltage PWM, by the means of the spectral analysis of the stator currents, to avoid the total dysfunction of the machine.

The general scheme of our study is given on figure 1 , it is constituted of a three levels PWM inverter which supply a permanent magnets synchronous machine with salient poles.

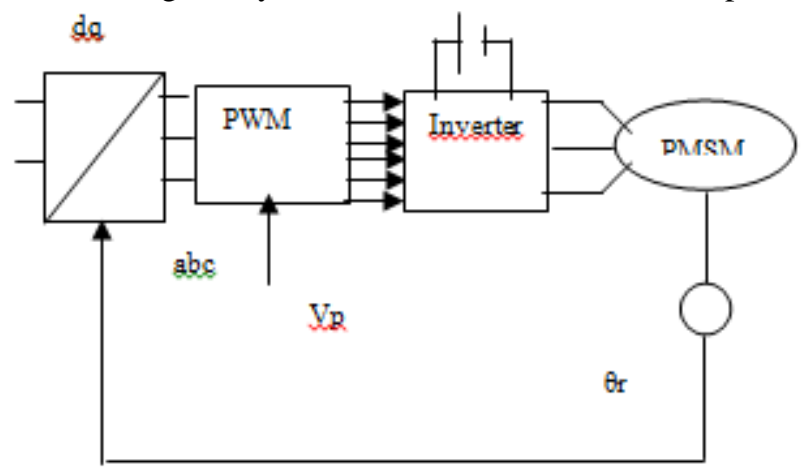

Fig. 1.Association of a PWM inverter with a PMSM

\section{INVERTER OF VOLTAGE ON THREE LEVELS}

Our machine is supplied with a three levels three-phase inverter PWM, whose general diagram is showed on figure 1 [Berkouk 95 ].

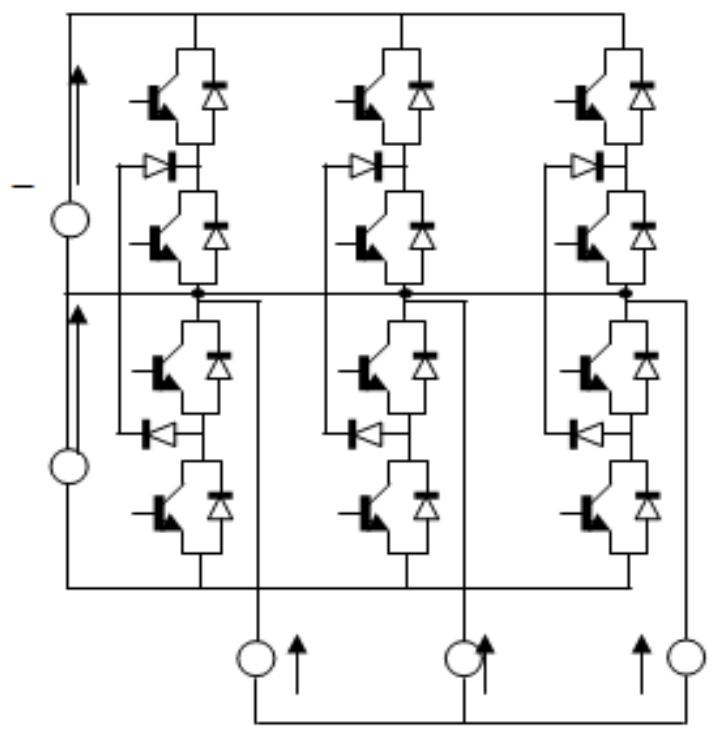

Fig. 2. General diagram of an inverter PWM on three levels 
The simple voltages are obtained starting from the following conditions:

If $\left(\mathrm{V}_{\text {réf }}=\mathrm{V}_{\mathrm{p}}\right)$ and $\left(\mathrm{V}_{\text {réf }}>0\right)=>\mathrm{V}_{\mathrm{K}}=+\mathrm{E} / 2$

If $\left(\mathrm{V}_{\text {réf }}=\mathrm{V}_{\mathrm{p}}\right)$ and $\left(\mathrm{V}_{\text {réf }}<0\right)=>\mathrm{V}_{\mathrm{K}}=-\mathrm{E} / 2$

If $\mathrm{V}_{\text {réf }}=\mathrm{V}_{\mathrm{p}}=>\mathrm{V}_{\mathrm{K}}=0$

With

$\mathrm{V}_{\text {réf: }}$ reference voltage standard;

$\mathrm{V}_{\mathrm{p}}$ : carrying;

$\mathrm{V}_{\mathrm{K}}$ : potential of the node $\mathrm{K}$.

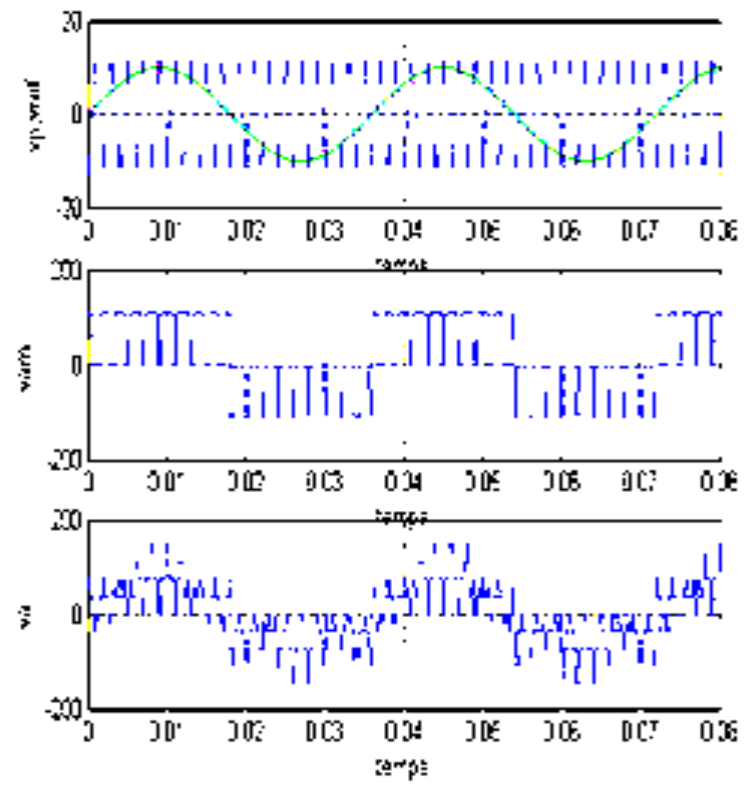

Fig. 3. Carrying reference, simple voltage, voltage of phase

III. MODEL OF THE SYNCHRONOUS MACHINE

The machine studied in this paper is with salient poles, the model that we retained after transformation of Park is as follows:

$=\left(\mathrm{V}_{\mathrm{ds}}-\mathrm{R}_{\mathrm{s}} \mathrm{I}_{\mathrm{ds}}+\omega_{\mathrm{r}} \mathrm{L}_{\mathrm{qs}} \mathrm{I}_{\mathrm{qs}}\right) / \mathrm{L}_{\mathrm{ds}} \frac{d I_{d s}}{d t}$

$=\left(\mathrm{V}_{\mathrm{qs}}-\mathrm{R}_{\mathrm{s}} \mathrm{I}_{\mathrm{qs}}-\omega_{\mathrm{r}} \mathrm{L}_{\mathrm{ds}} \mathrm{I}_{\mathrm{ds}}\right) / \mathrm{L}_{\mathrm{qs}} \frac{d I_{q s}}{d t}$

$\frac{d \omega_{r}}{d t}=p\left(C_{e m}-C_{r}\right) / J$

$C_{e m}=p\left(\phi_{r}+\left(L_{d s}-L_{q s}\right) I_{d s}\right) I_{q s}$

With

$\mathrm{R}_{\mathrm{s}}$ :stator resistant

$\mathrm{L}_{\mathrm{ds}}$ :inductance of direct axis
$\mathrm{L}_{\mathrm{qs}}$ :inductance of quadratic axis

$\mathrm{I}_{\mathrm{ds}}$ :current of direct axis

$\mathrm{I}_{\mathrm{q}}$ :current of quadratic axis

$\mathrm{V}_{\mathrm{ds}}$ :voltage of direct axis

$\mathrm{V}_{\mathrm{qs}}$ :voltage of quadratic axis

$\omega_{\mathrm{r}}$ :angular speed

$\Phi_{\mathrm{r}}$ :flow of permanent magnets

p:number of pair of poles

$\mathrm{C}_{\mathrm{em}}$ :electromagnetic torque

$\mathrm{C}_{\mathrm{r}}$ :resistant torque

$\mathrm{J}$ :Inertia of the machine

The speed, the torque and the spectra energy of a stator current of the safe machine supplied with the three levels inverter are showed on the following figure:
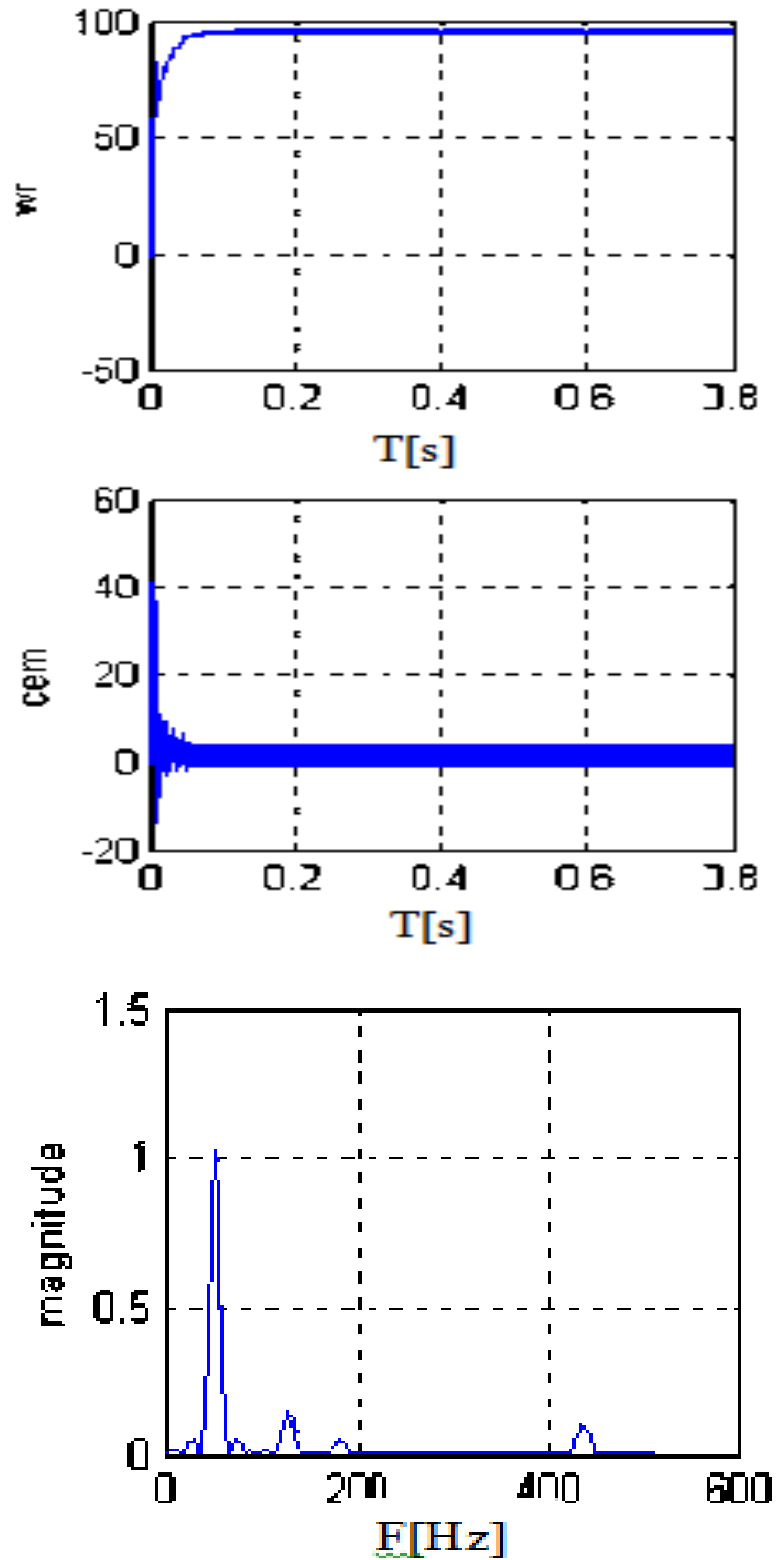

Fig. 4. Speed, electromagnetic torque and spectra energy of stator current in the safe motor 
IV. STUDY OF THE THREE-PHASE SHORT CIRCUIT

The short circuits between phases appear in rollings up of different phases standard, in the case of a course three-phase circuit they are the three rolling up which is touched. It is primarily the stator resistance which will

increase according to the number of whorls which will be short-circuited [Moreau 99 ].

- Case of : $30 \%$ of short circuit in phase A, $10 \%$ in the phase $\mathrm{B}$ and $20 \%$ in the phase $\mathrm{C}$ :
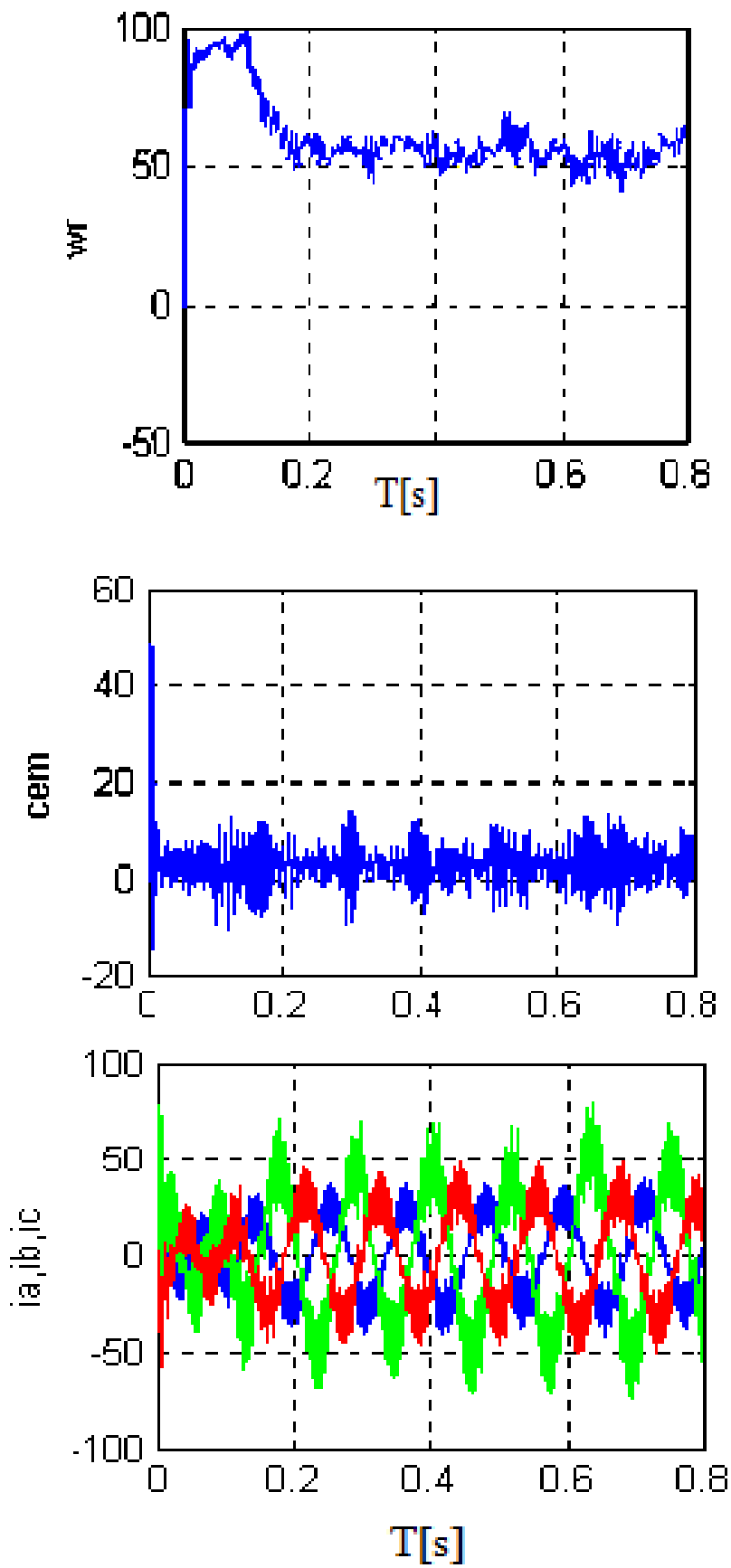

Fig. 5. Speed, torque, stator currents
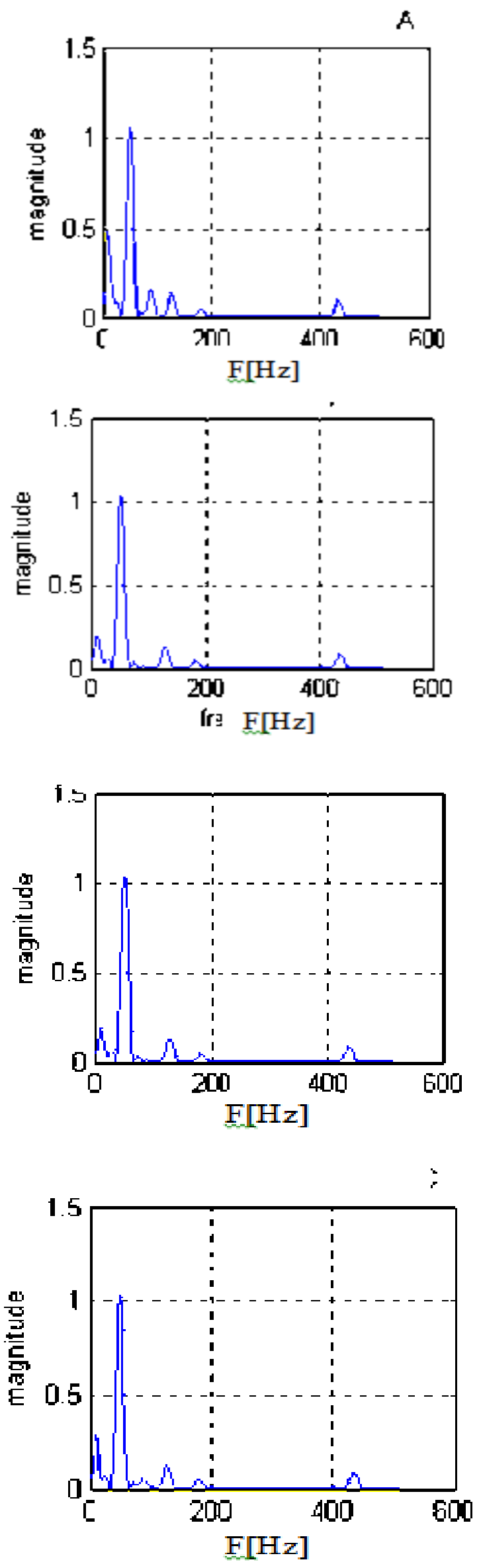
Fig. 6. Spectra energies of the stator currents

- Case of $30 \%$ of short circuit in all the phases
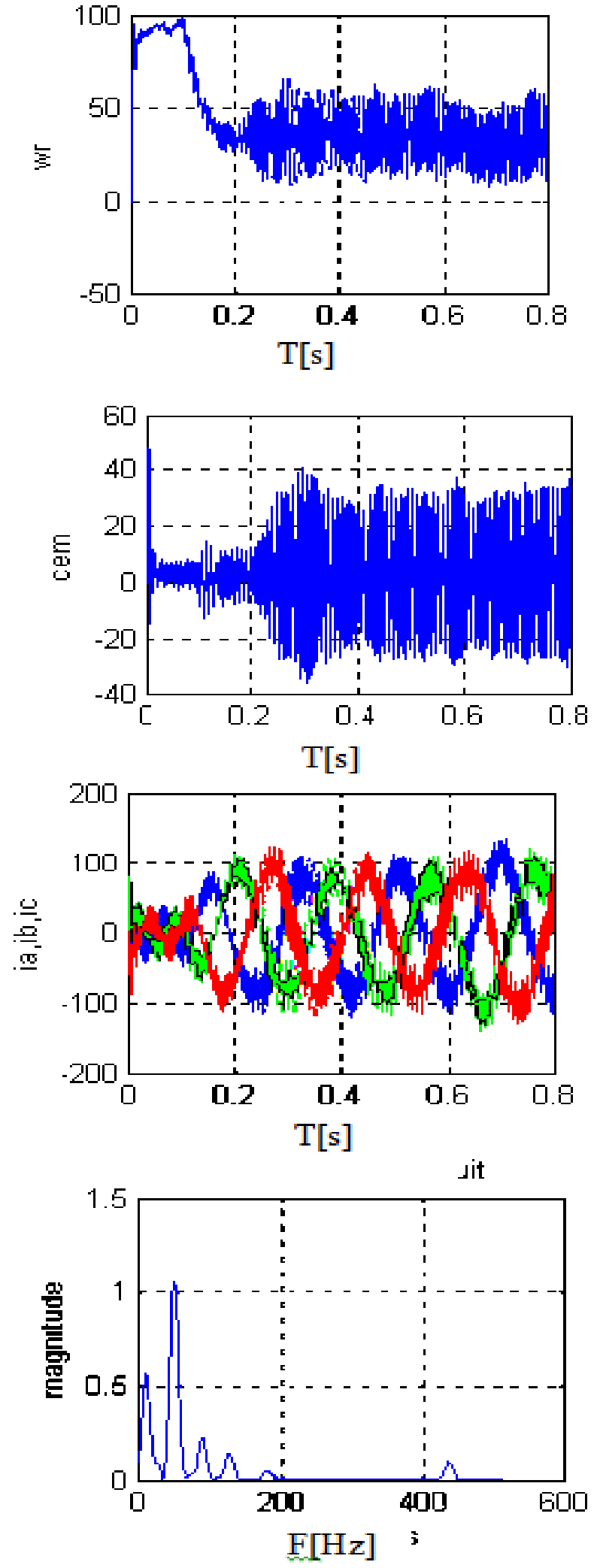

Fig. 7.Speed, torque, stator currents, spectra energy of the current

\section{RESUltS ANALYSIS}

The simulation has been done with Matlab software. Figure 4 presents angular speed, electromagnetic torque, and spectra of the current of the safe machine we remark that the spectra showes the fundamental harmonic and few others due to the inverter.

Figure 5 showes speed torque and stator currents of phase A, $\mathrm{B}$ and $\mathrm{C}$ in the case of $30 \%$ of short circuit in phase $\mathrm{A}, 10 \%$ in the phase $\mathrm{B}$ and $20 \%$ in the phase $\mathrm{C}$

And theirs respectives spetra are shown on figure 6 , we note the apparition of new harmonics around the fundamental one their amplitudes are proportional to the deffect. In figure 7 we present the case of $30 \%$ of short circuit in all the phases, the oscillations of both of speed, torque and currents have increased in relation to the last case. Speed is quantized in radian by second, torque by newton meter, and currents by ampere

\section{CONCLUSION}

A short circuit touchdown the three phases, would induce very strong currents which would lead to the fusion of the drivers, however, one short circuit near of the neutral generates an imbalance without causing the fusion of the drivers [ Boumegoura 01 ].

The appearance of a short circuit in stator winding generates an increase in the stator currents and the appearance of other harmonics in the latter, the average electromagnetic torque of the machine remains constant, although it is disturbed, having oscillations proportional to the defect.

Speed has also oscillations around its permanent value, the latter decreases with the increase in the extent of the defect..

\section{BIBLIOGRAPHY}

A conclusion section is usually required. Although a conclusion may review the main points of the paper, do not replicate the abstract as the conclusion. A conclusion might elaborate on the importance of the work or suggest applications and extensions. 